Audiology

Neurotology
Audiol Neurotol 2014;19:386-394

DOI: $10.1159 / 000363684$
Received: December 4, 2013

Accepted after revision: May 15, 2014

Published online: November 4, 2014

\title{
The Development of Auditory Perception in Children after Auditory Brainstem Implantation
}

\author{
Liliana Colletti $^{\mathrm{a}}$ Robert V. Shannon ${ }^{\mathrm{b}}$ Vittorio Colletti ${ }^{\mathrm{c}}$ \\ ${ }^{a}$ ENT Department, University of Verona, Italy; ${ }^{b}$ Department of Otolaryngology, University of Southern California, \\ Los Angeles, Calif., USA; ' International Center for Auditory Brainstem Implantation in Infants and Children, \\ Milan, Italy
}

\section{Key Words}

Auditory perception - Prelingually deaf children .

Cochlear malformation - Ossification - Fracture .

Cochlear nerve aplasia - Auditory brainstem implant .

Outcome $\cdot$ Auditory perception

\begin{abstract}
Auditory brainstem implants (ABIs) can provide useful auditory perception and language development in deaf children who are not able to use a cochlear implant $(\mathrm{Cl})$. We prospectively followed up a consecutive group of 64 deaf children up to 12 years following $A B I$ surgery. The etiology of deafness in these children was: cochlear nerve aplasia in 49, auditory neuropathy in 1, cochlear malformations in 8 , bilateral cochlear postmeningitic ossification in 3, neurofibromatosis type 2 in 2, and bilateral cochlear fractures due to a head injury in 1. Thirty-five children had other congenital nonauditory disabilities. Twenty-two children had previous Cls with no benefit. Fifty-eight children were fitted with the Cochlear $24 \mathrm{ABI}$ device and 6 with the MedEI ABI device, and all children followed the same rehabilitation program. Auditory perceptual abilities were evaluated on the Categories of Auditory Performance (CAP) scale. No child was lost to followup, and there were no exclusions from the study. All children showed significant improvement in auditory perception with implant experience. Seven children (11\%) were able to achieve the highest score on the CAP test; they were able to
\end{abstract}

converse on the telephone within 3 years of implantation. Twenty children (31.3\%) achieved open set speech recognition (CAP score of 5 or greater) and 30 (46.9\%) achieved a CAP level of 4 or greater. Of the 29 children without nonauditory disabilities, 18 (62\%) achieved a CAP score of 5 or greater with the ABI. All children showed continued improvements in auditory skills over time. The long-term results of $A B I$ surgery reveal significant auditory benefit in most children, and open set auditory recognition in many.

(c) 2014 S. Karger AG, Basel

\section{Introduction}

The time course for the development of auditory perception extends over many years even in normal-hearing children. Following an intervention such as that for a cochlear implant (CI) or auditory brainstem implant (ABI), long-term studies are necessary to evaluate the outcome [Nikolopoulos and O'Donoghue, 1998]. It is well known that prelingually deaf children make remarkable advances in auditory perception following CI insertion [Svirsky et al., 2000; Govaerts et al., 2002; Robbins et al., 2004; Manrique et al., 2004; Schauwers et al., 2004; Geers, 2004; Svirsky et al., 2004; Nicholas and Geers, 2007; Dettman et al., 2007; Colletti et al., 2011]. However, children with no auditory nerve, who are not candidates for a $\mathrm{CI}$, are a more difficult population because the central auditory re-

\section{KARGER}

E-Mail karger@karger.com

www.karger.com/aud
(C) 2014 S. Karger AG, Basel

$1420-3030 / 14 / 0196-0386 \$ 39.50 / 0$
Liliana Colletti, $\mathrm{PhD}$

ENT Department, University of Verona

Ospedale Civile Maggiore

Piazzale Aristide Stefani 1, IT-37126 Verona (Italy)

E-Mail collettiabi@yahoo.com 
gions of their brain may have never received input from the auditory periphery. In cases of developmental malformations, it is not clear if the remaining auditory system is sufficiently intact to support sound input from a prosthesis. Recent papers have shown encouraging results [Colletti, 2007; Eisenberg et al., 2008; Sennaroglu et al., 2009] from children receiving an ABI. The present paper provides results assessing the development of auditory perception in 64 young deaf children up to 12 years following an $\mathrm{ABI}$ insertion.

\section{Methods}

A consecutive group of 64 deaf children has been prospectively followed for up to 12 years following implantation with an ABI. Sixty of the children were prelingually deaf, and the age at implantation was less than 10 years. Four children were deafened from trauma or severe ossification after the onset of hearing. The radiological preoperative evaluation included a computed tomography (CT) scan and/or magnetic resonance imaging (MRI) scan showing the absence of a cochlear nerve. A thorough medical evaluation was performed before the decision for implantation. All parents were informed of the risks and potential benefits of the ABI and provided informed consent as approved by the local hospital human subjects review board. The etiology of deafness in these children was: cochlear nerve aplasia in 49 (21 of whom had been previously fitted elsewhere with a CI with no sound detection), auditory neuropathy in 1 (previously fitted with a CI elsewhere with no sound detection), cochlear malformations with 8th-nerve dysplasia in 3 ( 2 with Mondini type 2 bilateral incomplete cochlear partition and 1 with a common cavity), one of these with Crouzon syndrome, and 5 with severe cochlear abnormalities (4 cochlear aplasia and 1 child with only the cochlear basal turn), bilateral postmeningitic cochlear ossification in 3, bilateral cochlear fractures due to a head injury in 1, neurofibromatosis type 2 (NF2) in 2. Thirty-five children had additional nonauditory disabilities, and among these 9 had more than 1 disability: 8 children had mild motor disability, 8 behavioral impairment, 16 cognitive ( 8 with cognitive + other disabilities), 4 language and 2 visual impairment.

A retrosigmoid surgical approach was used in all children, all were fitted with either a Cochlear 24 ABI device $(n=58)$ or a MedEl ABI device $(n=6)$, and all followed the same rehabilitation program. Intraoperative and postoperative electrically evoked auditory brainstem responses (EABRs) were performed in all children. No child was lost to follow-up, and there were no exclusions from the study. All 64 children had reached the 1-year postimplantation stage and $56,53,43,35,28,22,15,14,10,5$ and 2 were assessed at the 2- to 12-year intervals, respectively.

Auditory perception was assessed with the Categories of Auditory Perception (CAP) test [Archbold et al., 1995, 1998], an 8-point hierarchical scale of auditory performance. The CAP scale ranges from no awareness of environmental sound (category 0 ) to conversational use of the telephone with a known speaker (category 7). The CAP was selected for this analysis because it is simple, easily administered and easily understood by speech therapists and audiologists as well as parents without experience in assessment methods for deaf children. Moreover it has been found to be highly reproducible across independent observers [Archbold et al., 1998], and it is an outcome measure able to cover the extremely wide range of the auditory performance observed in our preliminary studies on $\mathrm{ABI}$ surgery in children. It can be completed for all children, even the very young, taking also into consideration the different rates of development in these children. The Early Speech Perception and Glendonald Auditory Screening Procedure tests were used to evaluate the auditory performance of the 21 children implanted in other institutions outside Italy. The outcomes of these children were pooled together with the outcomes of the other 43 children by converting Early Speech Perception and Glendonald Auditory Screening Procedure scores into equivalent CAP scores according to performance level, e.g. discrimination of words in the Early Speech Perception test was assumed to be equivalent to category 4 on the CAP.

\section{Results}

The overall progress of the children fitted with an $\mathrm{ABI}$ is shown in table 1 , which shows the CAP score for the 64 children at each time interval. All children showed improvement in auditory perception with implant experience. There was considerable variability in outcomes, and further analysis was undertaken to determine the causes. ABI outcome was analyzed as a function of the top score obtained, the age at implantation, the presence or absence of nonauditory disabilities, and etiology.

Figure 1 shows the median CAP scores as a function of time, grouped by the top score achieved by each child. The 7 children (11\%) who ultimately were able to converse on the telephone (CAP level 7) all achieved this level by 3 years after ABI insertion. The 5 children (8\%) who achieved a CAP level of 6 also mostly achieved this level 3 years after ABI surgery. The 8 children (12.5\%) who achieved the lowest open set speech recognition CAP score of 5 took longer to achieve this level of performance - about 4 years. And the 10 children (16\%) who achieved closed set discrimination of words (CAP level 4) took 4-6 years to achieve this score. A total of 20 children (31\%) achieved some level of open set speech recognition with the ABI (CAP levels 5, 6 and 7) and almost half of the children $(30 / 64=47 \%)$ achieved CAP scores of 4 or better.

It is well known that age at implantation is an important factor in the success of CIs [Colletti et al., 2011; Dettman et al., 2007; Kirk et al., 2002; Manrique et al., 2004; Robbins et al., 2004; Svirsky et al., 2004]. It is important to supply sensory information to the developing brain while developmental plasticity is still strong. The present results were analysed to see if the information 
Table 1. CAP scores across years grouped by primary diagnosis

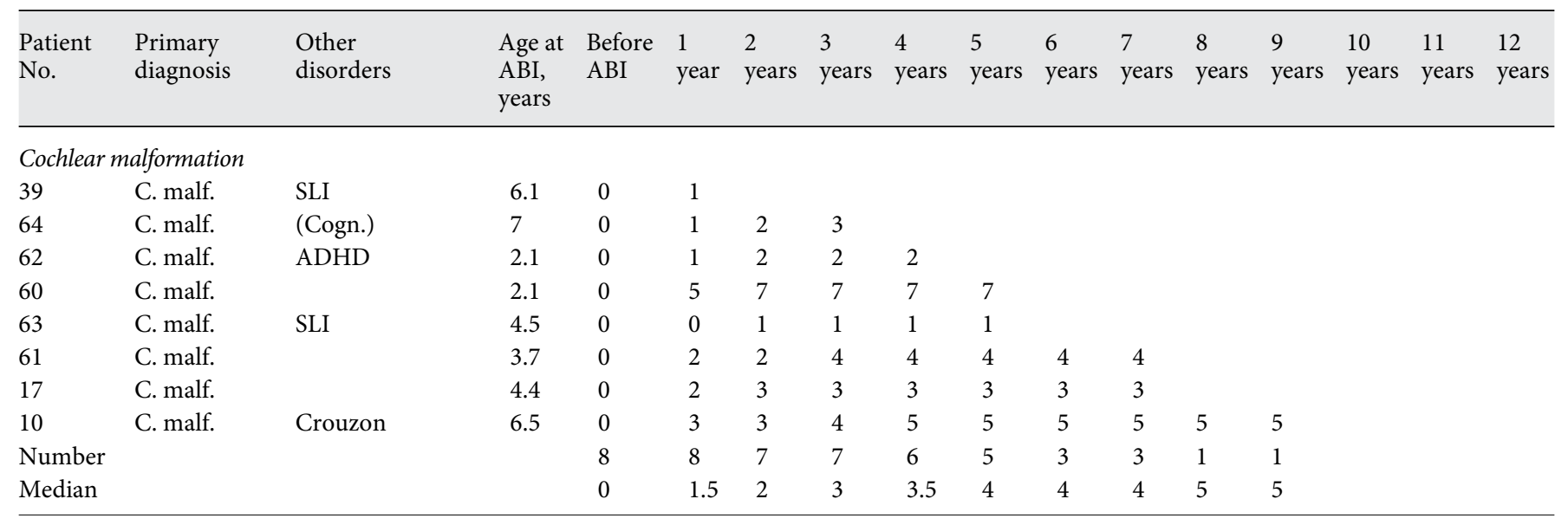

\begin{tabular}{|c|c|c|c|c|c|c|c|c|c|c|c|c|c|c|}
\hline \multicolumn{15}{|c|}{ Prior hearing } \\
\hline 29 & C. ossif. & 6.6 & 0 & 3 & 5 & 5 & & & & & & & & \\
\hline 6 & Ossif. & 2.8 & 0 & 5 & 6 & 7 & 7 & 7 & 7 & 7 & 7 & 7 & 7 & \\
\hline \multicolumn{3}{|c|}{ Number } & 4 & 4 & 4 & 4 & 3 & 3 & 3 & 2 & 2 & 2 & 2 & 1 \\
\hline \multicolumn{3}{|c|}{ Median } & 0 & 4.5 & 5.5 & 6 & 7 & 7 & 7 & 7 & 7 & 7 & 7 & 7 \\
\hline
\end{tabular}

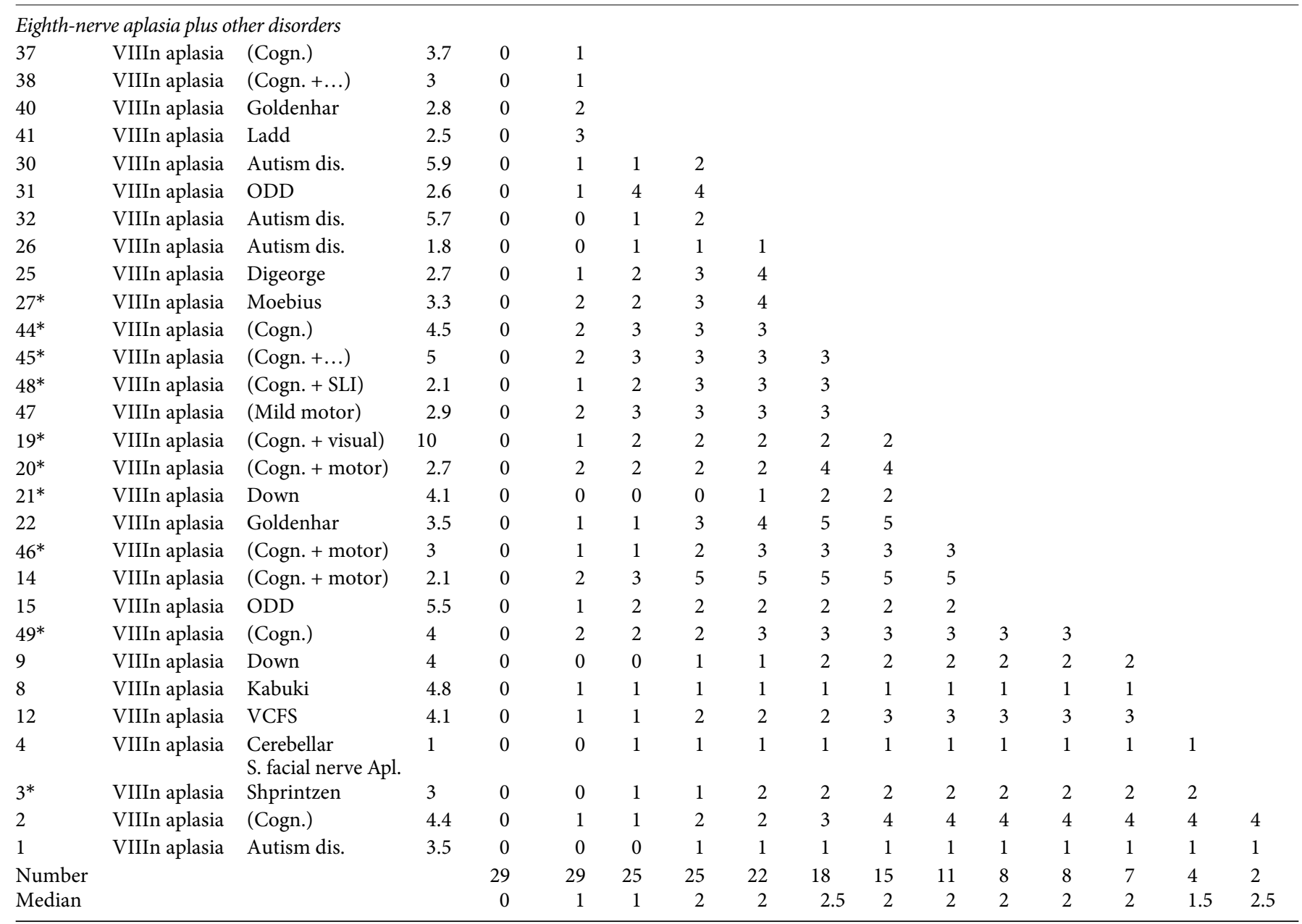


Table 1. (continued)

\begin{tabular}{|c|c|c|c|c|c|c|c|c|c|c|c|c|c|c|c|c|}
\hline $\begin{array}{l}\text { Patient } \\
\text { No. }\end{array}$ & $\begin{array}{l}\text { Primary } \\
\text { diagnosis }\end{array}$ & $\begin{array}{l}\text { Other } \\
\text { disorders }\end{array}$ & $\begin{array}{l}\text { Age at } \\
\text { ABI, } \\
\text { years }\end{array}$ & $\begin{array}{l}\text { Before } \\
\text { ABI }\end{array}$ & $\begin{array}{l}1 \\
\text { year }\end{array}$ & $\begin{array}{l}2 \\
\text { years }\end{array}$ & $\begin{array}{l}3 \\
\text { years }\end{array}$ & $\begin{array}{l}4 \\
\text { years }\end{array}$ & $\begin{array}{l}5 \\
\text { years }\end{array}$ & $\begin{array}{l}6 \\
\text { years }\end{array}$ & $\begin{array}{l}7 \\
\text { years }\end{array}$ & $\begin{array}{l}8 \\
\text { years }\end{array}$ & $\begin{array}{l}9 \\
\text { years }\end{array}$ & $\begin{array}{l}10 \\
\text { years }\end{array}$ & $\begin{array}{l}11 \\
\text { years }\end{array}$ & $\begin{array}{l}12 \\
\text { years }\end{array}$ \\
\hline
\end{tabular}

\section{Eighth-nerve aplasia only}

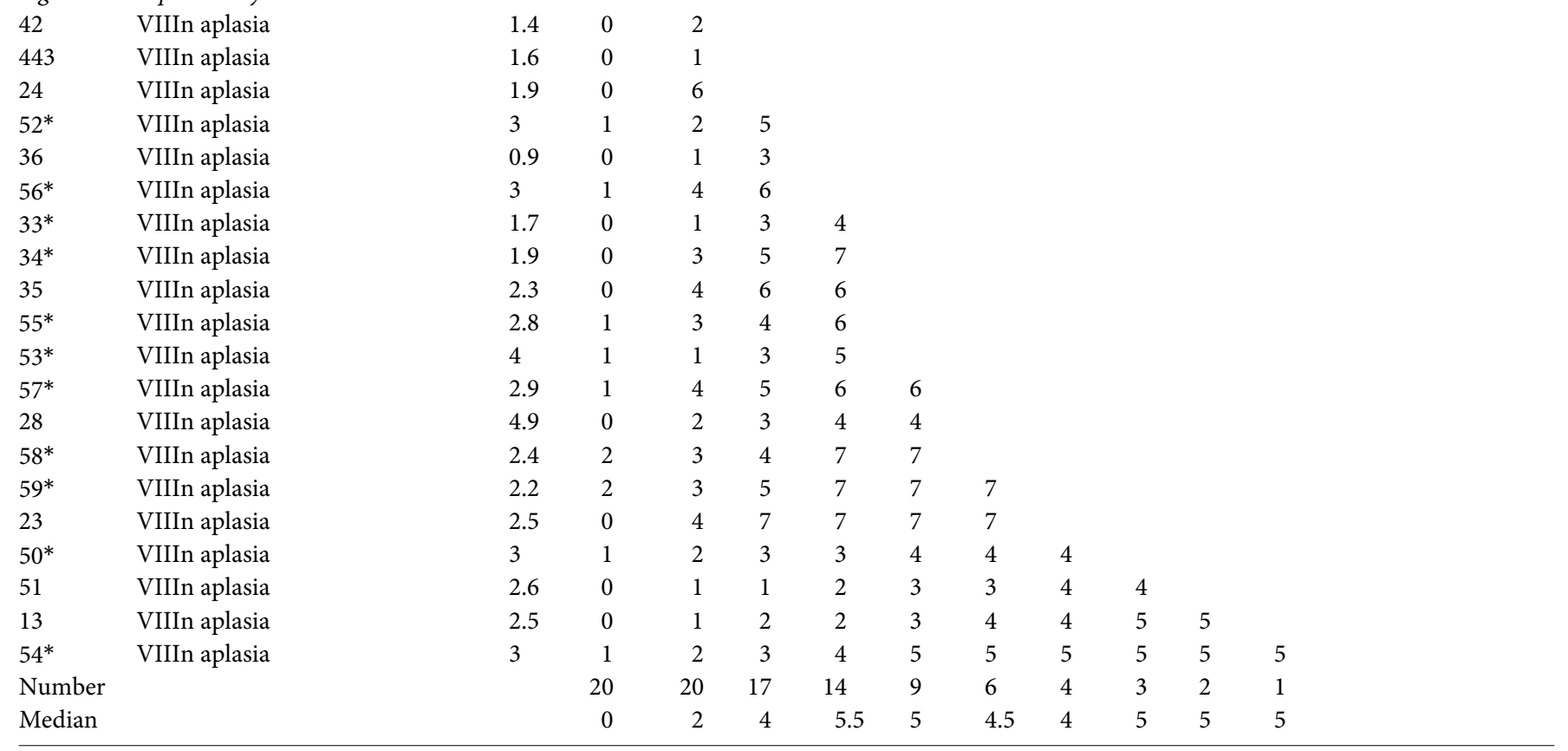

\section{NF2 or $A N$}

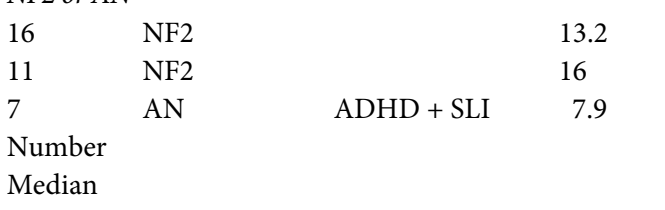

$\begin{array}{lllllllllll}0 & 1 & 1 & 1 & 1 & 1 & 1 & 1 & & & \\ 0 & 1 & 1 & 1 & 1 & 1 & 1 & 1 & 1 & 1 & \\ 0 & 1 & 1 & 2 & 2 & 2 & 2 & 2 & 2 & 2 & 2 \\ 3 & 3 & 3 & 3 & 3 & 3 & 3 & 3 & 2 & 2 & 1 \\ 0 & 1 & 1 & 1 & 1 & 1 & 1 & 1 & 1.5 & 1.5 & 2\end{array}$

CAP scores over time for all individual ABI children, grouped by primary diagnosis. CAP scores are presented by year, up to 12 years after implantation. An asterisk after the patient number indicates that this patient had a prior CI. C. malf. = Cochlear malformation; C. ossif. $=$ cochlear ossification; H. tr. = head trauma; VIIIn = 8th-nerve; $\mathrm{AN}=$ auditory neuropathy; SLI = specific language impairment; cogn. $=$ cognitive; $\mathrm{ADHD}=$ attention deficit hyperactivity disorder; dis. = disorder; ODD = oppositional defiant disorder; VCFS = velocardiofacial syndrome; S. = syndrome; Apl. = aplasia.

provided by an ABI also shows a sensitivity to age at implantation. Figure 2 shows the best CAP score achieved as a function of the age at ABI surgery. Only the 53 children who had used their ABI for at least 3 years are included in this plot to insure that performance was at or near the asymptotic level. Filled symbols show results from children without other disorders, while open symbols show results from children who had other disorders beyond deafness, such as motor or cognitive delays. As expected, there is a trend for better performance in children implanted at a younger age (Kendall's $\tau=-0.21$, $\mathrm{p}=0.027$ ). This is particularly clear in the children with no other disorders; many of these children implanted around the age of 2 were able to achieve a CAP score of 7. It is also clear that children without other disorders achieved higher asymptotic levels on the CAP than those with additional disorders (Cox regression time to event, additional disorders Wald $=34.2, \mathrm{p}<0.001$ ). It is possible that some of this difference is caused by children with additional disabilities needing more than 3 years to achieve asymptotic performance. However, 21 of the 30 children in this category had used the ABI more than 5 years (table 1 ).

One of the concerns with ABIs in congenitally deaf children is whether the congenital problems have involved the auditory portion of the brainstem. If there are 
developmental anomalies in the cochlear nucleus, then ABI stimulation may not be effective. In addition, some children with cognitive or other central processing disorders may not be able to effectively use the auditory information provided by the ABI [Pisoni, 2000]. We divided the results into two groups to investigate the effect of nonauditory complications on ABI performance: those children with other congenital abnormalities $(\mathrm{n}=35)$ and those without other complications $(n=29)$. Figure 3 shows the median CAP score for these two groups as a function of years after ABI. Children with no other disorders showed significantly higher CAP scores as a function of time (Kendall's $\tau=-0.57, \mathrm{p}<0.001$ ). Three years after $\mathrm{ABI}$ there was a 3-category difference in the median CAP score between the two groups. This suggests that at least some nonauditory congenital anomalies can limit the potential benefit of an ABI, either from direct effect on the auditory brainstem or on central processing necessary to make use of the ABI information. Although children with other disabilities achieved low scores on the CAP, they still showed improved awareness of their environment and improvements in cognitive development [Colletti and Zoccante, 2008]. Also note that while the median CAP score was only 2 for those children with additional disabilities, a few children in this category did obtain CAP scores of 4 or 5 (table 1 ).

Probably the most important issue in the application of $A B I$ in children is the effect of etiology on outcomes. We divided the 64 cases into 5 etiology groups: children who had prior hearing but lost it due to trauma or severe ossification $(n=4)$, children with congenital deafness due to cochlear nerve aplasia $(n=20)$, cochlear malformations $(\mathrm{n}=8)$, cochlear nerve aplasia with other nonauditory disabilities $(\mathrm{n}=29)$ and NF2 and auditory neuropathy $(\mathrm{n}=3)$. Children in this last category were considerably older at the time of ABI surgery (average age 9 years) than children in other categories. Figure 4 shows the median CAP score for each etiology group as a function of years of ABI use. While there appear to be clear differences in the median CAP scores between etiology groups, the top and bottom curves have too few subjects to achieve statistical significance, and the middle 3 curves did not achieve significant differences due to the high variability in performance within each etiology group. The 4 children who had prior hearing (3 cochlear ossification, 1 trauma) clearly had the best outcomes, increasing in performance rapidly over the first 3 years and ultimately reaching the highest CAP level. The dashed line reproduces data from a study reporting CAP results for 53 children with cochlear implants

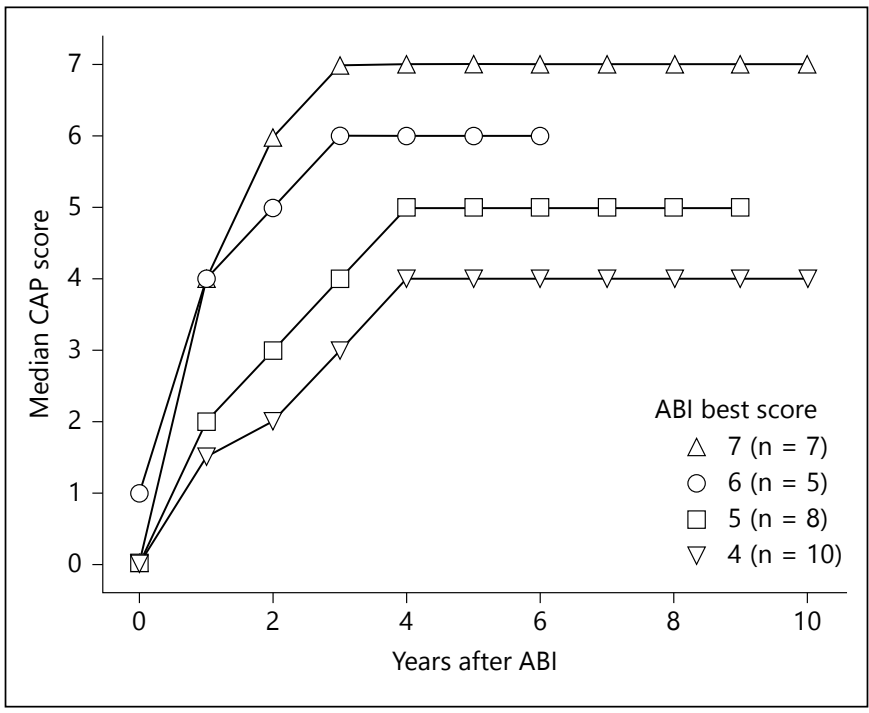

Fig. 1. Median pediatric ABI scores on the CAP test over time. Results are grouped by the highest score ultimately achieved for categories 4-7.

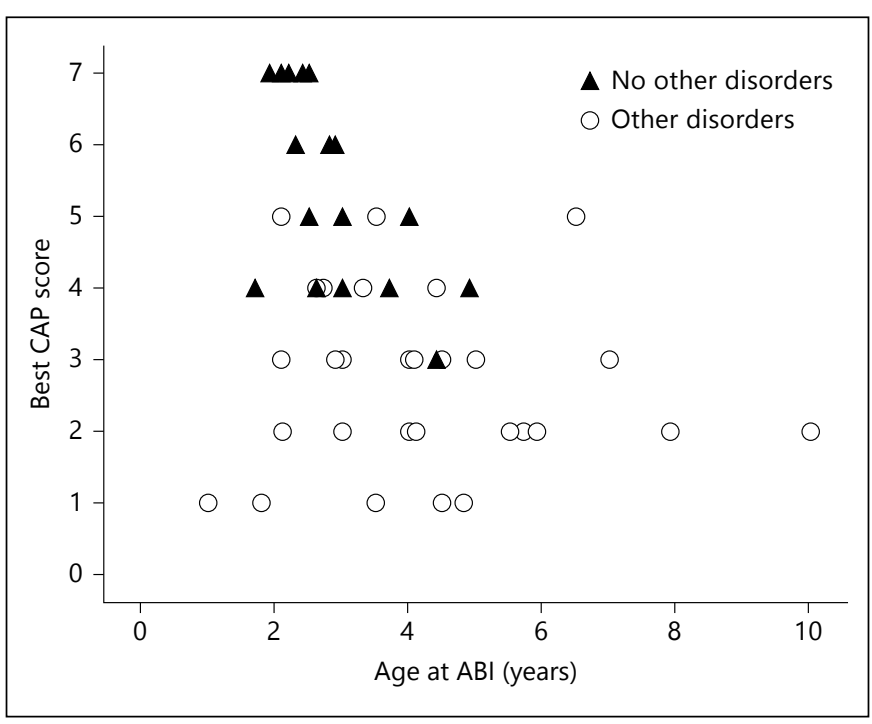

Fig. 2. Best ABI CAP scores as a function of the age at implantation. Open symbols represent children with additional disabilities. Filled symbols indicate children with no additional disabilities. Only the 53 children who had the ABI at least 3 years and were under 10 years of age at the time of implantation are included.

[Archbold et al., 1995], showing a similar trajectory of improvement compared to ABI recipients with prior hearing. This suggests that the highest performing ABI children can advance in auditory development at a rate similar to children with CIs. Similar observations have 


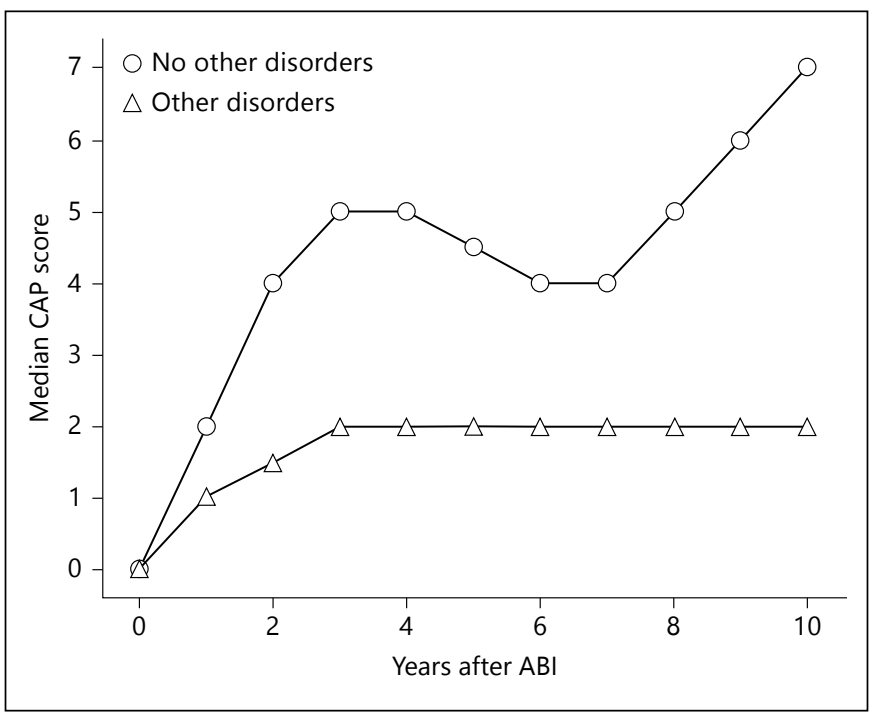

Fig. 3. Median pediatric ABI CAP scores over time grouped according to other disorders. Children with no other disorders only had cochlea or cochlear nerve pathologies. Other disorders include a variety of congenital disorders listed in table 1 . The numbers of children at each follow-up year for the two groups are as follows. For the group 'No other disorders': 29, 29, 26, 23, 17, 14, 11, 9, 5, 4,2 for years $0-10$, respectively; for the group 'Other disorders': 35 , $35,30,30,26,21,17,13,10,10,8$ for years $0-10$, respectively.

been reported in $2 \mathrm{ABI}$ children by Eisenberg et al. [2012].

A Cox time series survival analysis evaluated the time it took to achieve a CAP score of 5 - the lowest level of open set speech recognition. Sixty-one of the patients were grouped in two different ways: cochlear versus neural point of origin, and no additional disabilities versus additional disabilities. Three patients who were more than 10 years old at the time of ABI surgery were not included in the analysis. The time needed to achieve CAP level 5 was not significantly related to the point of origin of the hearing loss: cochlear versus neural. However, the presence of additional disabilities was a significant predictor of the time to achieve CAP level 5 ( $\mathrm{p}<0.0001)$, regardless of whether the main deficit was of cochlear origin or nerve origin.

Twenty-one children with cochlear and cochlear nerve aplasia had been previously fitted with a CI and subsequently received an $\mathrm{ABI}$. These children all showed significant improvements with the ABI compared to the CI: median CAP score of 1 with CI versus 4 with ABI ( $\mathrm{p}<$ $0.001)$. Nine of the $21(43 \%)$ achieved open set speech recognition (CAP scores 5,6 or 7 ) with the ABI, while none of the 21 had achieved this level with a CI.

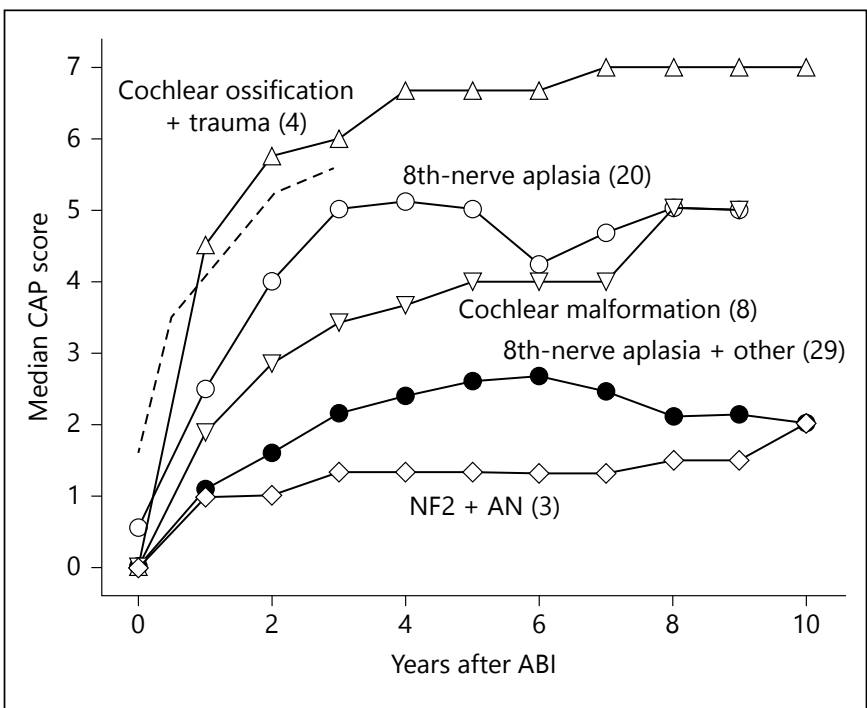

Fig. 4. Median pediatric ABI scores on the CAP test over time grouped by primary diagnosis. $\mathrm{AN}=$ Auditory neuropathy. The numbers in parentheses after each category indicate the number of children in that category 1 year after implantation. Numbers of children in each category diminish with years. Actual numbers at each year are found in table 1 . The dashed line reproduces CAP scores over time from 53 children with a CI from Archbold et al. [1995].

\section{Discussion}

A consecutive group of 64 deaf children were followed up to 12 years following ABI surgery. Within 1 year of activation $87.5 \%$ of the children had obtained awareness of environmental sounds and $48.4 \%$ responded to speech sounds. Within 2 years of activation $23.4 \%$ of children were able to identify environmental sounds and discriminate speech sounds (CAP level 4). Of the 53 children with 3-year follow-up data, 26.4\% were able to understand common phrases without the aid of lip reading and $13.2 \%$ of the children could use the telephone with a known speaker. This study confirms previous findings that the $\mathrm{ABI}$ is an appropriate device for auditory (re)habilitation in children with cochlear and cochlear nerve malfunctions that cannot benefit from CIs.

A comparison of the ABI outcomes obtained from this series of children versus a large group of children fitted with CIs clearly shows better performance outcomes obtained in a shorter time period in the CI group [Niparko et al., 2010]. However, when CI results are compared with $\mathrm{ABI}$ children who have heard before, then performance is comparable and the developmental trajectory is comparable (fig. 4 , top curves). In addition, when ABI perfor- 
mance is compared with congenitally deaf children who received a CI at the same age, then performance levels and trajectory over time are similar [Eisenberg et al., 2012]. This group of $\mathrm{ABI}$ children had previous hearing but lost their auditory nerve from head trauma or severe ossification following meningitis. This result suggests that the ABI could be considered as a next step for children with progressive ossification. In some cases a CI can provide adequate hearing for a time, but then the ossification may progress to damage the spiral ganglion in the modiolus and CI performance may drop dramatically. These children may regain open set speech recognition with an ABI.

\section{Developmental Urgency}

In our sample, none of the children with cochlear nerve aplasia or hypoplasia who had a CI first showed satisfactory auditory development with a CI. In such cases the time spent trying out the CI was not only time (and expense) wasted, but also caused a prolongation of the period of auditory deprivation. Physiological sensory deprivation studies have demonstrated that in the absence of auditory stimulation, neural structures show a failure to mature and can degenerate [Nadol et al., 1989; Moore et al., 1994; Ponton et al., 1996; Shepherd et al., 1997], and auditory cortical areas can be reallocated to other modalities [Lee et al., 2001; Giraud and Lee, 2007].

When should a trial with a CI be skipped and move directly to an ABI? Under what conditions can we be confident that a CI will not provide useful hearing? Recent studies of CI outcomes in children have shown clear etiologies where CI results can be poor [Buchman et al., 2011; Young et al., 2012]. In cases where no auditory nerve is visible on high-resolution CT images of the internal auditory meatus and when the EABR evoked by the $\mathrm{CI}$ is distorted or absent, auditory results were very poor. In such cases, an $\mathrm{ABI}$ may provide better performance than a CI. We recommend high-resolution CT imaging of the internal auditory meatus [Govaerts et al., 2003; Casselman et al., 2008; Carner et al., 2009] and EABRs, stimulated either through an existing CI or from a wick electrode on the round window. In cases where the auditory nerve is not visible and there is no reliable EABR, it may be a waste of time and expense to implant a CI or to continue to wait for auditory progress.

\section{Neural Plasticity}

It is of critical importance to have auditory input during the period of greatest neural plasticity in order to develop speech perception. There is compelling evidence that outcomes are better when CIs are provided at the youngest age
[Svirsky et al., 2000; Kirk et al., 2002; Govaerts et al., 2002; Robbins et al., 2004; Schauwers et al., 2004; Svirsky et al., 2004; Manrique et al., 2004; Waltzman and Roland, 2005; Dettman et al., 2007; Colletti et al., 2011]. We assume that this plasticity is primarily determined in the central system (e.g. auditory cortex), and so we assume that a similar time pressure exists for children to receive the $\mathrm{ABI}$ as early as possible. Children who receive CIs below the age of 1 have clearly better and more rapid auditory development than children who receive CIs between 1 and 2 years of age. And CIs in 2- to 3-year-olds give better outcomes than those in children implanted at ages greater than 3 years. So if a CI is tried initially, clinicians must remain vigilant for the early signs of CI efficacy. If no progress is being made on simple auditory tasks, it may be necessary to move to an $\mathrm{ABI}$ as soon as possible to make the best use of that early neural plasticity. It is necessary to explant the CI, re-evaluate the child with neuroimaging studies and perform $\mathrm{ABI}$ surgery as soon as possible after the lack of progress with a CI has become evident. Children previously fitted with CIs and subsequently with ABIs may demonstrate a slower development of auditory perception, possibly because of the major difference in the neural pattern of activation from the two devices and possibly because the time window of plasticity has partially closed.

\section{Cognitive Factors}

We cannot explain why some children with the ABI can detect and discriminate environmental sounds but do not develop speech perception and language. It may be hypothesized that one or more of the following conditions are responsible for the poor or low progression in speech perception abilities: incorrect positioning of the ABI array, incomplete development of the cochlear nuclei and auditory areas undetected by MRI, degeneration of cochlear nuclear cells specialized for processing speech, programming difficulties and inadequate encoder strategy, or other negative psychological and cognitive factors.

Pisoni [2000] has suggested that psychological and cognitive factors might play as important a role as perception in the development of speech perception. Most of the children in this study who had associated psychological and cognitive deficits could perceive the sounds and discriminate some speech patterns only a few months after ABI fitting. However, their overall auditory perceptual development has been very slow, and they continue to have trouble translating the electrical stimulation into speech and language development. Additional intervention by psychologists and psycholinguists may be necessary to design specific rehabilitative strategies to help 
these children convert the new auditory sensations from the $\mathrm{ABI}$ into speech and language.

Even if children are not able to achieve open set speech recognition with the $\mathrm{ABI}$, they may receive cognitive benefits. Access to auditory information from the ABI has been demonstrated [Colletti, 2007; Colletti and Zoccante, 2008] to influence the development of specific cognitive functions. Scores on two tests evaluating cognitive function (form completion and repeated patterns) increased significantly during the first 12 months of $\mathrm{ABI}$ use. These data demonstrated that the fitting of the $\mathrm{ABI}$ in preverbal children with activation of the auditory sensory channel, previously absent, facilitated the development of cognitive parameters related to selective visual-spatial attention and fluid (multisensory) reasoning.

\section{Safety and Complications}

It is clear that the potential for surgical complications is greater for an $\mathrm{ABI}$ than for a $\mathrm{CI}$. ABI surgery is an intradural procedure with some compression of the cerebellum in the retrosigmoid approach. For this reason we recommend that ABIs in children be only attempted in centers with trained pediatric surgical teams with experience in the retrosigmoid approach. In our clinic we found that the actual rate of surgical and device complications for an ABI were similar to those seen in CI surgery [Colletti et al., 2010]. The higher rate of complications observed in $\mathrm{ABI}$ surgery in adults was primarily related to NF2, the most common etiology for adult ABIs. In non-NF2 adults and in children, the complication rate was low - comparable to the complication rate observed for the same surgical approach for microvascular decompression. From the long-term follow-up in the present data set, we can report that we have observed no additional long-term complications from ABI placement and stimulation. To ensure this excellent safety record we stress that $\mathrm{ABI}$ in children should only be undertaken in experienced centers trained specifically for $A B I$ in children.

\section{Conclusions}

The ABI can provide beneficial auditory sensations to congenitally deaf children. The best outcomes with the $\mathrm{ABI}$ are in children who have heard before, either following severe meningitic ossification or trauma. Open set speech recognition was also observed in children with cochlear nerve aplasia and in children with severe cochlear malformations. Significant auditory benefit, but without open set speech recognition, was observed in children with cochlear nerve aplasia plus syndromic nonauditory disabilities. In some cases of severe cochlear ossification, the $\mathrm{ABI}$ may provide better access to the remaining auditory nerve and superior performance to a CI. In cases of retrocochlear damage the $\mathrm{ABI}$ provides access to sound and allows steady improvements in sound discrimination and recognition. In all cases the $\mathrm{ABI}$ provides additional auditory input that allows improvements in auditory and cognitive development. It is important to implant the ABI as early as possible to take advantage of the powerful developmental plasticity of the brain. The ABI should be considered as a valuable tool in restoring auditory function to children for whom a CI is not an option.

\section{Acknowledgements}

We thank the children and their families for their commitment and persistence in this trial. We also thank Laurel Fisher for her help with statistical analysis of the data. R.V.S. was partially supported by a grant from the National Institute on Deafness and Other Communication Disorders.

\section{References}

-Archbold SM, Lutman E, Marshall D: Categories of auditory performance. Ann Otol Rhinol Laryngol 1995;104(suppl 166):312314.

Archbold SM, Lutman E, Nikolopoulos T: Categories of auditory performance: inter-user reliability. Br J Audiol 1998;32:7-12.

- Buchman CA, Teagle HF, Roush PA, Park LR, Hatch D, Woodard J, Zdanski C, Adunka OF: Cochlear implantation in children with labyrinthine anomalies and cochlear nerve deficiency: implications for auditory brainstem implantation. Laryngoscope 2011;121:1979-1988.
Carner M, Colletti V, Shannon R, Cerini R, Barillari M, Colletti L: Imaging in 28 children with cochlear nerve aplasia. Acta Otolaryngol 2009;129:458-461.

Casselman J, Mermuys K, Delanote J, Ghekiere J, Coenegrachts K: MRI of the cranial nerves more than meets the eye: technical considerations and advanced anatomy. Neuroimaging Clin North Am 2008;18:197-231,

Colletti L: Beneficial auditory and cognitive effects of auditory brainstem implantation in children. Acta Otolaryngol 2007;127:943946.
Colletti L, Mandalà M, Zoccante L, Shannon RV, Colletti V: Infants versus older children fitted with cochlear implants: performance over 10 years. Int J Pediatr Otorhinolaryngol 2011;75: 504-509.

Colletti L, Zoccante L: Nonverbal cognitive abilities and auditory performance in children fitted with auditory brainstem implants: preliminary report. Laryngoscope 2008;118:1443-1448.

-Colletti V, Shannon RV, Carner M, Veronese S, Colletti L: Complications in auditory brainstem implant surgery in adults and children. Otol Neurotol 2010;31:558-564. 
-Dettman L, Pinder D, Briggs R, Dowell R, Leigh J: Communication development in children who receive the cochlear implant younger than 12 months: risks versus benefits. Ear Hear 2007;28:11S-18S.

-Eisenberg LS, Johnson KC, Martinez AS, DesJardin JL, Stika CL, Dzubak D, Mahalak ML, Rector EP: Comprehensive evaluation of a child with an auditory brainstem implant. Otol Neurotol 2008;29:251-257.

- Eisenberg LS, Johnson KC, Martinez AS, VisserDumont L, Ganguly DH, Still JF: Studies in pediatric hearing loss at the House Research Institute. J Am Acad Audiol 2012;23:412-421.

Geers AE: Speech, language, and reading skills af ter early cochlear implantation. Arch Otolaryngol Head Neck Surg 2004;130:634-638.

- Giraud AL, Lee HJ: Predicting cochlear implant outcome from brain organisation in the deaf. Restor Neurol Neurosci 2007;25:381-390.

-Govaerts PJ, Casselman J, Daemers K, De Beukelaer C, Yperman M, De Ceulaer G: Cochlear implants in aplasia and hypoplasia of the cochleovestibular nerve. Otol Neurotol 2003;24: 887-891.

-Govaerts PJ, De Beukelaer C, Daemers K, De Ceulaer G, Yperman M, Somers T, Schatteman I, Offeciers FE: Outcome of cochlear implantation at different ages from 0 to 6 years. Otol Neurotol 2002;23:885-890.

-Kirk KI, Miyamoto RT, Lento CL, Ying E, O'Neill T, Fears B: Effects of age at implantation in young children. Ann Otol Rhinol Laryngol Suppl 2002;189:69-73.

-Lee DS, Lee JS, Oh SH, Kim SK, Kim JW, Chung JK, Lee MC, Kim CS: Cross-modal plasticity and cochlear implants. Nature 2001;409:149150.
Manrique M, Cevera-Paz FJ, Huarte A, Molina M: Advantages of cochlear implantation in prelingual deaf children before 2 years of age when compared to later implantation. Laryngoscope 2004;114:1462-1469.

Moore JK, Niparko JK, Miller MR, Linthicum FH: Effect of profound hearing loss on a central auditory nucleus. Am J Otol 1994;15:588595.

Nadol JB, Young YS, Glynn RJ: Survival of spiral ganglion cells in profound sensorineural hearing loss: implications for cochlear implantation. Ann Otol Rhinol Laryngol 1989; 98:411-416.

Nicholas JG, Geers AE: Will they catch up? The role of age at cochlear implantation in the spoken language development of children with severe to profound hearing loss. J Speech Lang Hear Res 2007;50:1048-1062.

-Nikolopoulos TP, O’Donoghue GM: Cochlear implantation in adults and children. Hosp Med 1998;59:46-49.

- Niparko JK, Tobey EA, Thal DJ, Eisenberg LS, Wang NY, Quittner AL, Fink NE; CDaCI Investigative Team: Spoken language development in children following cochlear implantation. JAMA 2010;303:1498-1506.

Pisoni D: Cognitive factors and cochlear implants: some thoughts on perception, learning, and memory in speech perception. Ear Hear 2000;21:70-78.

Ponton CW, Don M, Eggermont JJ, Waring MD, Masuda A: Maturation of human cortical auditory function: differences between normalhearing children and children with cochlear implants. Ear Hear 1996;17:430-437.

Robbins KM, Koch DB, Osberger MJ, Zimmerman-Phillips S, Kishon-Rabin L: The effect of age at cochlear implantation on auditory skill development in infants and toddlers. Arch Otolaryngol Head Neck Surg 2004;130:570574.
Schauwers A, Gilis S, Daemers K, DeBeukelar C, Govaerts P: Cochlear implantation between 5 and 20 months of age: the onset of babbling and the audiologic outcome. Otol Neurotol 2004;25:263-270.

Sennaroglu L, Ziyal I, Atas A, Sennaroglu G, Yucel E, Sevinc S, Ekin MC, Sarac S, Atay G, Ozgen B, Ozcan OE, Belgin E, Colletti V, Turan E: Preliminary results of auditory brainstem implantation in prelingually deaf children with inner ear malformations including severe stenosis of the cochlear aperture and aplasia of the cochlear nerve. Otol Neurotol 2009;30:708-715.

Shepherd RK, Hartmann R, Heid S, Hardie N, Klinke R: The central auditory system and auditory deprivation: experience with cochlear implants in the congenitally deaf. Acta Otolaryngol Suppl 1997;532:28-33.

Svirsky MA, Robbins AM, Kirk KI, Pisoni DB, Miyamoto RT: Language development in profoundly deaf children with cochlear implants, Psychol Sci 2000;11:153-158.

Svirsky MA, Teoh SW, Neuberger H: Development of language and speech perception in congenitally, profoundly deaf children as a function of age at cochlear implantation. Audiol Neurotol 2004;9:224-233.

Waltzman S, Roland JT: Cochlear implantation in children younger than 12 months. Pediatrics 2005; 116:487-493.

Young NM, Kim FM, Ryan ME, Tournis E, Yaras S: Pediatric cochlear implantation of children with eighth nerve deficiency. Int J Pediatr Otorhinolaryngol 2012;76:1442-1448. 